\title{
An fNIRS examination of the neural correlates of mental rotation in preschoolers
}

\author{
Dandan $\mathrm{Wu}^{1 \dagger}$, Jinfeng $\mathrm{Yang}^{2 \dagger}$, Sha Xie ${ }^{3}$, Jiutong Luo ${ }^{3}$, Chunqi Chang ${ }^{2 *}$, Hui $\mathrm{Li}^{1 *}$
}

\begin{abstract}
This study examined the neural correlates of mental rotation (MR) in preschoolers using functional near-infrared spectroscopy (fNIRS). Fortyeight preschoolers completed a MR task in which they were asked to rotate a test stimulus to match a target stimulus. Results of comparative and General Linear Model (GLM) analyses revealed significant differences between the High Performance (HP) and Low Performance (LP) groups. The two groups differed significantly in oxyhaemoglobin ( $\mathrm{HbO}$ ) change in Brodmann Areas (BAs) 6, 9 and 44 . Specifically, significant increase in $\mathrm{HbO}$ in BA 44 was observed in both groups, while significant decrease in deoxyhaemoglobin (HbR) in BA 9 was observed only in the HP group and in BA 44 only in the LP group. These results jointly indicated BA 44 as one of the core neural correlates of MR in preschoolers, while BA 6 and BA 9 might also be involved in MR processing under a compensatory mechanism.
\end{abstract}

Keywords: neural correlates, mental rotation, compensatory mechanism, Chinese preschoolers

\section{INTRODUCTION}

Mental rotation (MR) is a cognitive process of imaging and mentally rotating an object (1) and has been one of the best research paradigms to evaluate early cognitive development (2). In the first and pioneering study on MR, Shepard and Metzler (1) employed pairs of drawings of three-dimensional, asymmetrical assemblages of cubes and found that the reaction time to decide whether the two objects depicted were in fact identical (except for rotation) or were mirror images increased with the angular rotation difference between the pairs (2). Since then, considerable efforts have been made to identify brain regions activated in MR (3). Recent studies have identified significant activation in the frontal cortex (Brodmann Area (BA) 9, BA 44), premotor cortex (BA 6) and parietal cortex (BA 40) during MR (4-6). All these studies, however, were conducted with adult participants (3). So far, the neural correlates of MR in preschoolers have not been explored with neuroimaging technologies.

Furthermore, the existing studies on MR in preschoolers are constrained to the traditional behavioural paradigm. For instance, Frick, Ferrara and Newcombe (7) assessed individual differences in MR abilities of preschoolers aged between 3.5 and 5.5 years. They found that error rate and response time increased linearly with increasing angular disparity by the age of 5. Both manual and observational experience improved response accuracy of preschoolers at the age of 5 but not 4 . These results indicated that successful application of the MR paradigm should be restricted to children aged 5 and above. Later, Kruger et al. (8) developed a new research paradigm (a touchscreen task), allowing for the measurement and interpretation of reaction time with children aged 3 to 6 . They found that preschoolers aged 3 and 4 performed reliably above the chance but only those aged 5 and 6 successfully completed the entire task. However, none of these studies adopted neuroimaging technologies such as EEG and fMRI.

The past decade has seen a rapid increase in the use of fNIRS in cognitive neuroscience. fNIRS is portable, silent, tolerant to bodily movements and suitable for preschoolers when they are performing tasks both inside and outside the laboratory. Therefore, for the first time, we used fNIRS to monitor brain activity by measuring changes in haemoglobin concentrations in the outer cortex when preschoolers were performing MR. In particular, the following

${ }^{1}$ Macquarie University, Australia. ${ }^{2}$ Shenzhen University, China. ${ }^{3}$ The University of Hong Kong, Hong Kong SAR, China.

$\dagger$ These authors contributed equally to this work.

*Corresponding authors. Email: cqchang@szu.edu.cn (C.C.), philip.li@mq.edu.au (H.L.) questions guided this study: 1 . What are the significant differences between the High Performance (HP) and Low Performance (HP) preschoolers indicated by fNIRS evidence? 2. What are the brain areas involved in the MR according to fNIRS evidence?

\section{RESULTS}

Group Differences in Oxyhaemoglobin ( $\mathrm{HbO})$ and Deoxyhaemoglobin (HbR) Changes

First, a set of two-sample (independent groups) $t$-tests was conducted to determine any significant difference in $\mathrm{HbO}$ increase between the HP and LP groups.

Table 1. Comparison of Increases in $\mathrm{HbO}$ between the High Performance (N1=18) and Low Performance (N2=18) Groups in the Mental Rotation Task

\begin{tabular}{|c|c|c|c|c|c|}
\hline$R O I$ & Group & Mean & $S D$ & T Value & $p$ value \\
\hline \multirow[t]{2}{*}{ Channel 1} & High & -1.812 & 1.904 & -1.676 & .103 \\
\hline & Low & -7.196 & 2.004 & & \\
\hline \multirow[t]{2}{*}{ Channel 2} & High & -1.214 & 1.755 & .331 & .743 \\
\hline & Low & -1.453 & 2.499 & & \\
\hline \multirow[t]{2}{*}{ Channel 3} & High & -1.063 & 2.125 & -1.775 & .085 \\
\hline & Low & .486 & 3.030 & & \\
\hline \multirow[t]{2}{*}{ Channel 4} & High & -1.357 & 1.852 & .900 & .375 \\
\hline & Low & -2.169 & 3.350 & & \\
\hline \multirow[t]{2}{*}{ Channel 5} & High & .625 & 3.076 & .661 & .513 \\
\hline & Low & -.100 & 3.491 & & \\
\hline \multirow[t]{2}{*}{ Channel 6} & High & -.612 & 1.696 & -2.216 & $.033^{*}$ \\
\hline & Low & .851 & 2.230 & & \\
\hline \multirow[t]{2}{*}{ Channel 7} & High & -.257 & 2.058 & -.228 & .821 \\
\hline & Low & -.077 & 2.653 & & \\
\hline \multirow[t]{2}{*}{ Channel 8} & High & .030 & 2.554 & -.042 & 967 \\
\hline & Low & . .067 & 2.855 & & \\
\hline \multirow[t]{2}{*}{ Channel 9} & High & -2.802 & 3.257 & -2.960 & $.006^{*}$ \\
\hline & Low & -.118 & 2.046 & & \\
\hline \multirow[t]{2}{*}{ Channel 10} & High & -1.533 & 3.396 & -.557 & .581 \\
\hline & Low & -1.006 & 2.136 & & \\
\hline \multirow[t]{2}{*}{ Channel 11} & High & -2.327 & 2.519 & -1.119 & .271 \\
\hline & Low & -1.419 & 2.346 & & \\
\hline \multirow[t]{2}{*}{ Channel 12} & High & -2.400 & 2.523 & .894 & .378 \\
\hline & Low & -3.014 & 1.460 & & \\
\hline \multirow[t]{2}{*}{ Channel 13} & High & -3.286 & 3.474 & -1.893 & .067 \\
\hline & Low & -1.419 & 2.333 & & \\
\hline \multirow[t]{2}{*}{ Channel 14} & High & -2.915 & 2.699 & -2.376 & $.023^{*}$ \\
\hline & Low & -.803 & 2.635 & & \\
\hline \multirow[t]{2}{*}{ Channel 15} & High & -2.436 & 3.824 & -1.285 & .207 \\
\hline & Low & -1.184 & 1.573 & & \\
\hline \multirow[t]{2}{*}{ Channel 16} & High & -2.682 & 2.804 & -2.562 & $.015^{*}$ \\
\hline & Low & -.625 & 1.933 & & \\
\hline \multirow[t]{2}{*}{ Channel 17} & High & -3.687 & 2.604 & -1.701 & .098 \\
\hline & Low & -2.364 & 2.027 & & \\
\hline
\end{tabular}


The results indicated a significant between-group difference in BA 44 (ch 6) $(t=-2.22, p<.05)$, BA 6 (ch 9) $(t=-2.96, p<$ $.01)$, BA 9 (ch 14) $(t=-2.38, p<.05)$ and BA 9 (ch 16) $(t=-$ $2.56, p<.05)$. As shown in Table 1 , significantly less decrease in $\mathrm{HbO}$ was observed in BA 6 (ch 9) and BA 9 (ch $14 \&$ 16) in the LP group compared to the HP group. Critically, an increase in $\mathrm{HbO}$ was observed in the LP group while a decrease in $\mathrm{HbO}$ was observed in the HP group in BA 44 (ch 6), indicating more brain activation in this area this during MR for the LP group only.

Next, a set of two-sample (independent groups) $t$-tests was conducted to determine any significant difference in HbR decrease between the HP and LP groups. No significant between-group difference was found in any of the channels, $t \mathrm{~s}<1.06, p \mathrm{~s}\rangle .20$.

\section{Predicting $\mathrm{HbO}$ Increase for High and Low Performance Groups}

A set of GLM analyses was conducted to predict the change in $\mathrm{HbO}$ $(\Delta \mathrm{HbO})$ in the 17 channels based on experiment time for the High and Low Performance groups separately. In the HP group, as shown in Table 2, significant $\mathrm{HbO}$ increase was observed in ch 5 (BA 44) $\left[\beta=.47, \Delta R^{2}=.22, F=42.46\right.$ (for the model), $t=6.52$ (for $\beta$ ), $p \mathrm{~s}<.001]$ and ch 7 (BA 44) $\left[\beta=.41, \Delta R^{2}=.16, F=29.59\right.$ (for the model), $t=5.44$ (for $\beta$ ), $p$ s $<.001]$. Meanwhile, significant decrease in $\mathrm{HbO}$ was observed in all other channels, $F \mathrm{~s}>4.99$ (for the models), $t \mathrm{~s}>-2.23$ (for $\beta$ ), $p \mathrm{~s}<.01$.

Table 2. Predicting HbO Increase for the High Performance Group (N1=18) and Low Performance Group (N2 = 18) in the Mental Rotation Task

\begin{tabular}{|c|c|c|c|c|}
\hline Channel & $\beta$ & $\Delta R^{2}$ & $F$ Value & $T$ Value \\
\hline \multicolumn{5}{|c|}{ High Performance Group $\left(N_{H P}=18\right)$} \\
\hline $\mathrm{Ch} 1$ & -.226 & .045 & $7.965^{* *}$ & $-2.822 * *$ \\
\hline $\mathrm{Ch} 2$ & -.548 & .296 & $63.564^{* * *}$ & $-7.973 * * *$ \\
\hline $\mathrm{Ch} 3$ & -.546 & .294 & $62.904 * * *$ & $-7.931 * * *$ \\
\hline $\mathrm{Ch} 4$ & -.200 & .034 & $6.185^{*}$ & $-2.487^{*}$ \\
\hline Ch5 & .472 & .218 & $42.464 * * *$ & $6.516 * * *$ \\
\hline Ch6 & -.835 & .695 & $339.733 * * *$ & $-18.432^{* * * *}$ \\
\hline $\mathrm{Ch} 7$ & .408 & .161 & $29.587 * * *$ & $5.439 * * *$ \\
\hline $\mathrm{Ch} 8$ & -.671 & .446 & $121.090^{* * *}$ & $-11.004 * * *$ \\
\hline Ch9 & -.831 & .690 & $329.500 * * *$ & $-18.152 * * *$ \\
\hline Ch10 & -.181 & .026 & $4.993 *$ & $-2.234 *$ \\
\hline Ch11 & -.794 & .628 & $252.798 * * *$ & $-15.900 * * *$ \\
\hline Ch12 & -.792 & .625 & $249.296 * * *$ & $-15.789 * * *$ \\
\hline Ch13 & -.883 & .777 & $521.408 * * *$ & $-22.834 * * *$ \\
\hline Ch14 & -.550 & .297 & $64.068 * * *$ & $-8.004 * * *$ \\
\hline Ch15 & -.927 & .860 & $908.315^{* * *}$ & $-30.135^{* * *}$ \\
\hline Ch16 & -.580 & .332 & $75.191^{* * *}$ & $-8.671^{* * *}$ \\
\hline Ch17 & -.804 & .643 & $269.866^{* * *}$ & $-16.428 * * *$ \\
\hline \multicolumn{5}{|c|}{ Low Performance Group $\left(N_{L P}=18\right)$} \\
\hline Ch1 & .499 & .244 & $49.105^{* * *}$ & $7.007 * * *$ \\
\hline $\mathrm{Ch} 2$ & -.289 & .077 & $13.517 * * *$ & $-3.677 * * *$ \\
\hline $\mathrm{Ch} 3$ & .584 & .336 & $76.412^{* * *}$ & $8.741^{* * *}$ \\
\hline $\mathrm{Ch} 4$ & -.424 & .174 & $32.353^{* * *}$ & $-5.688 * * *$ \\
\hline Ch5 & .796 & .631 & $255.582 * * *$ & $15.987 * * *$ \\
\hline Ch6 & .020 & -.006 & .060 & .244 \\
\hline $\mathrm{Ch} 7$ & -.563 & .312 & $68.576^{* * *}$ & $-8.281 * * *$ \\
\hline Ch8 & .350 & .117 & $20.703 * * *$ & $4.550 * * *$ \\
\hline Ch9 & -.707 & .499 & $147.673 * * *$ & $-12.152 * * *$ \\
\hline Ch10 & -.986 & .972 & $5221.160 * * *$ & $-72.258 * * *$ \\
\hline Ch11 & -.262 & .062 & $10.912 * *$ & $-3.303 * *$ \\
\hline Ch12 & -.575 & .326 & $73.009 * * *$ & $-8.545^{* * * *}$ \\
\hline Ch13 & -.935 & .874 & $1023.874 * * *$ & $-31.998 * * *$ \\
\hline Ch14 & -.605 & .362 & $85.564 * * *$ & $-9.250 * * *$ \\
\hline Ch15 & -.616 & .376 & $90.625 * * *$ & $-9.520 * * *$ \\
\hline Ch16 & -.487 & .232 & $46.093^{* * *}$ & $-6.789 * * *$ \\
\hline Ch17 & -.724 & .521 & $463.069 * * *$ & $-12.770 * * *$ \\
\hline
\end{tabular}

Table 3. Predicting HbR Decrease for the High Performance Group (N1=18) and Low Performance Group (N2=18) in the Mental Rotation Task

\begin{tabular}{|c|c|c|c|c|}
\hline Channel & $\beta$ & $\Delta R^{2}$ & $F$ Value & $T$ Value \\
\hline \multicolumn{5}{|c|}{ High Performance Group $\left(N_{H P}=18\right)$} \\
\hline Ch1 & .307 & .088 & $15.349 * * *$ & $3.918 * * *$ \\
\hline $\mathrm{Ch} 2$ & .894 & .797 & $586.723 * * *$ & $24.222 * * *$ \\
\hline Ch3 & .727 & .526 & $166.043 * * *$ & $12.886^{* * * *}$ \\
\hline $\mathrm{Ch} 4$ & -.153 & .017 & 3.553 & -1.885 \\
\hline Ch5 & .851 & .722 & $388.343 * * *$ & $19.706 * * *$ \\
\hline Ch6 & .738 & .541 & $176.722 * * *$ & $13.294 * * *$ \\
\hline $\mathrm{Ch} 7$ & .969 & .939 & $2306.591 * * *$ & $48.027 * * *$ \\
\hline Ch8 & .816 & .665 & $294.257^{* * *}$ & $17.154 * * *$ \\
\hline Ch9 & .931 & .866 & $964.629 * * *$ & $31.058^{* * *}$ \\
\hline Ch10 & .943 & .889 & $1196.700^{* * *}$ & $34.593 * * *$ \\
\hline Ch11 & .721 & .517 & $160.282^{* * *}$ & $12.660^{* * *}$ \\
\hline Ch12 & -.846 & .714 & $372.382 * * *$ & $-19.297 * * *$ \\
\hline Ch13 & .959 & .918 & $1676.629^{* * *}$ & $40.947^{* * *}$ \\
\hline Ch14 & -.315 & .093 & $16.270^{* * *}$ & $-4.034 * * *$ \\
\hline Ch15 & .141 & .013 & 2.985 & 1.728 \\
\hline Ch16 & -.382 & .141 & $25.362 * * *$ & $-5.036 * * *$ \\
\hline Ch17 & .682 & .462 & $128.797 * * *$ & $11.349 * * *$ \\
\hline \multicolumn{5}{|c|}{ Low Performance Group $\left(N_{L P}=18\right)$} \\
\hline Ch1 & .551 & .299 & $64.488^{* * *}$ & $8.030^{* * *}$ \\
\hline $\mathrm{Ch} 2$ & .916 & .837 & $766.426 * * *$ & $27.684 * * *$ \\
\hline $\mathrm{Ch} 3$ & .896 & .801 & $600.845^{* * *}$ & $24.512 * * *$ \\
\hline $\mathrm{Ch} 4$ & .629 & .392 & $97.137^{* * *}$ & $9.856^{* * *}$ \\
\hline Ch5 & -.255 & .059 & $10.264^{* *}$ & $-3.204^{* *}$ \\
\hline Ch6 & .821 & .672 & $306.483^{* * *}$ & $17.507 * * *$ \\
\hline $\mathrm{Ch} 7$ & .936 & .875 & $1041.172^{* * *}$ & $32.267 * * *$ \\
\hline Ch8 & .879 & .770 & $501.195 * * *$ & $22.387 * * *$ \\
\hline Ch9 & .925 & .855 & $882.363 * * *$ & $29.705^{* * *}$ \\
\hline Ch10 & .966 & .932 & $2053.202^{* * *}$ & $45.312 * * *$ \\
\hline Ch11 & .965 & .931 & $2009.369^{* * *}$ & $44.826^{* * *}$ \\
\hline Ch12 & .410 & .163 & $29.966^{* * *}$ & $5.474 * * *$ \\
\hline Ch13 & .972 & .944 & $2515.998^{* * *}$ & $50.160^{* * *}$ \\
\hline Ch14 & .817 & .665 & $297.201 * * *$ & $17.240 * * *$ \\
\hline Ch15 & .950 & .902 & $1374.481^{* * *}$ & $37.074 * * *$ \\
\hline Ch16 & .958 & .917 & $1641.013^{* * *}$ & $40.509 * * *$ \\
\hline Ch17 & .869 & .754 & $456.916^{* * *}$ & $21.376^{* * * *}$ \\
\hline
\end{tabular}

In the HP group, as shown in Table 3, significant decrease in $\mathrm{HbR}$ was observed in ch 12 (BA 9) $\left[\beta=-.85, \Delta R^{2}=.71, F=372.38\right.$ (for the model), $t=-19.30$ (for $\beta$ ), $p$ s $<.001]$, ch 14 (BA 9) $[\beta=$ -.32, $\Delta R^{2}=.09, F=16.27$ (for the model), $t=-4.03$ (for $\beta$ ), $p \mathrm{~s}<$ $.001]$ and ch 16 (BA 9) $\left[\beta=-.38, \Delta R^{2}=.14, F=25.36\right.$ (for the model), $t=-5.04$ (for $\beta$ ), $p$ s $<.001]$. Meanwhile, no significant $\mathrm{HbR}$ change was observed in ch 4 (BA 40) and ch 15 (BA 10), $F \mathrm{~s}<3.56$ (for the models), $t \mathrm{~s}<1.89$ (for $\beta$ ), $p \mathrm{~s}<.01$. However,

In the LP group, as shown in Table 2, significant increase in $\mathrm{HbO}$ was observed in ch 1 (BA6) $\left[\beta=.499, \Delta R^{2}=.244, F=49.11\right.$ (for the model), $t=7.01$ (for $\beta$ ), $p \mathrm{~s}<.001]$, ch 3 (BA44) $[\beta=.584$, ch 5 (BA44) $\left[\beta=.796, \Delta R^{2}=.631, F=255.58\right.$ (for the model), $t=$ 15.99 (for $\beta$ ), $p$ s <.001] and ch 8 (BA44) $\left[\beta=.350, \Delta R^{2}=.117\right.$, $F=20.70$ (for the model), $t=4.55$ (for $\beta$ ), $p$ s $<.001]$. Meanwhile,
significant HbO decrease was observed in all other channels, $F \mathrm{~s}>$ 10.91 (for the models), $t \mathrm{~s}>-3.30$ (for $\beta$ ), $p$ s $<.01$, except ch 6 (BA 44) which showed no significant change in $\mathrm{HbO}$ (See Table 2).

A set of GLM analyses was conducted to predict the change in HbR $(\triangle \mathrm{HbR})$ in the 17 channels based on experiment time for the HP and LP groups separately. 
Table 4. Observed Activation by fNIRS in the Mental Rotation Task

\begin{tabular}{|c|c|c|c|c|c|c|c|c|c|c|c|c|c|c|c|c|c|}
\hline Group & & & & & & & & & ianr & & & & & & & & \\
\hline & 1 & 2 & 3 & 4 & 5 & 6 & 7 & 8 & 9 & 10 & 11 & 12 & 13 & 14 & 15 & 16 & 17 \\
\hline \multicolumn{18}{|l|}{ Mental Rotation } \\
\hline High Performance (HbO) & & & & & + & & + & & & & & & & & & & \\
\hline High Performance (HbR) & & & & & & & & & & & & - & & - & & - & \\
\hline Low Performance (HbO) & + & & + & & + & & & + & & & & & & & & & \\
\hline Low Performance (HbR) & & & & & - & & & & & & & & & & & & \\
\hline$T$ test & & & & & & $X$ & & & $X$ & & & & & $X$ & & $X$ & \\
\hline Brodmann Area (BA) & 6 & 44 & 44 & 40 & 44 & 44 & 44 & 44 & 6 & 8 & 9 & 9 & 10 & 9 & 10 & 9 & 10 \\
\hline
\end{tabular}

+ Significant increase in $\mathrm{HbO} ;-$ Significant decrease in $\mathrm{HbR} ; \boldsymbol{X}$ Significant group difference

significant $\mathrm{HbR}$ increase was found in all of the remaining channels [ $F \mathrm{~s}>15.34$ (for the models), $t \mathrm{~s}>3.91$ (for $\beta$ ), $p \mathrm{~s}<.01]$.

In the LP group, as shown in Table 3, significant HbR increase was observed in all channels, $F \mathrm{~s}>29.96$ (for the models), $t \mathrm{~s}>5.47$ (for $\beta$ ), $p \mathrm{~s}<.01$, except ch 5 (BA44) which showed a significant HbR decrease, $\beta=-.26, \Delta R^{2}=.06, F=10.26$ (for the model), $t=$ -3.20 (for $\beta$ ), $p$ s $<.01$.

In summary, as shown in Table 4, the $t$-tests and GLM results jointly indicated the following group differences: (1) significant difference in $\mathrm{HbO}$ change was observed between the HP and LP groups in BA 6 (ch 9), BA 9 (ch $14 \& 16$ ) and BA 44 (ch 6); (2) significant increase in $\mathrm{HbO}$ in $\mathrm{BA} 44$ (ch $5 \& 7$ ) as well as significant decrease in $\mathrm{HbR}$ in BA 9 (ch 12,14 \& 16) were observed in the HP group; and (3) significant increase in $\mathrm{HbO}$ in BA 6 (ch 1) and BA 44 (ch 3, 5 \& 8) as well as significant decrease in HbR in BA 44 (ch 5) were observed in the LP group. Note the critical concurrent $\mathrm{HbO}$ increase and $\mathrm{HbR}$ decrease in $\mathrm{BA} 44$ (ch 5) in the LP group.

\section{DISCUSSION}

\section{Two Patterns of Neural Correlates during Mental Rotation}

The present study found two distinctive neural patterns during MR in Chinese preschoolers. Pattern I, demonstrated by the High Performance (HP) group, was an adultlike neural pattern with significant $\mathrm{HbO}$ increase in $\mathrm{BA} 44$ (ch 5 \& 7) as well as significant HbR decrease in BA 9 (ch 12, 14 \& 16). Pattern II, observed in the Low Performance (LP) group, showed significant $\mathrm{HbO}$ increase in BA 6 (ch 1) and BA 44 (ch 3, 5 \& 8) as well as significant HbR decrease in BA 44 (ch 5). In other words, both significant $\mathrm{HbO}$ increase and significant $\mathrm{HbR}$ decrease were observed in BA 44 (ch 5) in the LP group. Comparative analyses revealed significant difference in HbO change in BA 6 (ch 9), BA 9 (ch 14 \& 16) and BA 44 (ch 6) between the two groups, with only BA44 showing a significant increase in $\mathrm{HbO}$ in the LP Group (Pattern II). These results indicated substantial involvement of BA 44 in the two neural patterns, suggesting that BA 44 might be one of the core neural correlates for MR.

Why does BA 44 play a decisive role in MR? Existing research findings converge to indicate the significant functions of BA44 in binding elements of the language, selecting information among competing sources, generating/extracting action meanings, as well as in the cognitive control mechanism for syntactic processing of sentences (9). In addition, BA 44 has also been implicated in hand movements $(10)$ and cognitive shifting in the dimensional change card sort (DCCS) task in preschool children (11). In this study, preschoolers were required to make hand movements in order to rotate the test stimulus to match the unrotated one on the table. Since all the participants were right-handed, the activation observed in BA 44 in the right hemisphere would not be attributed to movements of their right hands. We therefore rule out its role in hand movements but affirm its critical role in mental rotation, at least in the current study.

In addition to BA44 (activated by adults in previous studies and by both the HP and LP groups in the present study), BA6 was also activated by the LP group during MR, consistent with existing literature (4-6). BA 6 is part of the frontal agranular cortex - rostral to the primary motor cortex - and is believed to mediate a transition from motor to cognitive functions (12). BA 6, considered to be the conjunction of interaction between cognitive information processing and motor control, is involved in both cognitive and motor functions (13). All these findings, however, were generated from adult studies. This study, for the first time, demonstrated the involvement of BA 6 in MR in preschoolers.

Finally, significantly less decrease in $\mathrm{HbO}$ was observed in BA9 in the LP group compared to the HP group. BA9 in the right hemisphere has been implicated in attributing intention, theory of mind, working memory, spatial memory, recognition, recall and planning (14-20). In the current study, we speculate that the LP preschoolers recruited BA 9 to assist BA 44 in coping with the cognitive demands during mental rotation. Here, we put forward an analogous explanation in terms of the neural compensatory mechanism proposed by Yoon et al. (21) who demonstrated significantly higher activation in the right prefrontal cortex and suggested it as a compensatory effect to supplant the left prefrontal function in Stroop tasks. However, due to different cognitive requirements between the Stroop tasks and the present task, further studies are needed to verify this compensatory mechanism in MR.

\section{Concurrent Increase in $\mathrm{HbO}$ and Decrease in $\mathrm{HbR}$}

fNIRS technology provides concentration changes of two signals, oxyhaemoglobin ( $\mathrm{HbO}$ ) and deoxyhaemoglobin ( $\mathrm{HbR})$, each with its advantages and disadvantages. $\mathrm{HbO}$ is the most sensitive indicator of changes in regional cerebral blood flow, whereas $\mathrm{HbR}$ is the best indicator of the neuronal activity. Theoretically, functional 
activation of a given brain area is reflected by concurrent increase in $\mathrm{HbO}$ and decrease in $\mathrm{HbR}$ and interpretation of results should be drawn based on these concurrent changes (22). However, rarely have concurrent changes in both $\mathrm{HbO}$ and $\mathrm{HbR}$ been used in the literature. There is also a lack of agreement as to which of $\mathrm{HbO}$ or $\mathrm{HbR}$ would make a better indication of functional activity in cognitive neuroscience research (22).

In the current study, concurrent significant $\mathrm{HbO}$ increase and significant $\mathrm{HbR}$ decrease were only observed in BA 44 (ch 5) for the LP group. Following Pinti et al.'s theoretical proposition (22), our findings indicate that BA 44 is one of the core neural correlates of MR, at least for the LP group. Given the fact that the fNIRS community is still concerned about the extent to which fNIRSderived signals $\mathrm{HbO}$ and/or $\mathrm{HbR}$, can be used to infer functional brain activity, we call for additional research to aid the establishment of guidelines and automated procedures for analysis of fNIRS data, so that accurate inferences and precise localisation of brain functions can be made.

\section{Conclusions, Limitations and Implications}

In summary, significant differences in brain activation were observed between the HP and LP groups. Firstly, the $t$-tests and GLM results jointly indicated significant group difference in $\mathrm{HbO}$ change in BA 6, BA 9 and BA 44, suggesting differential involvement of these areas between groups during MR. Secondly, the HP Group showed significant activation of BA 44 but significant HbR decrease in BA 9, indicating the central role of BA44 in MR in HP preschoolers. Thirdly, the LP group showed significant activation of BA 6 and BA 44 as well as significant HbR decrease in BA 44, again pointing towards the central role of BA44 in MR. Altogether, the results converge to suggest that BA 44 is one of core neural correlates involved in preschoolers' MR performance and that BA 6 and BA 9 are also involved, possibly under a compensatory mechanism.

This study, however, has some limitations. Firstly, the core brain area involved in the current MR task is BA44. However, this area has also been implicated in the control of hand movements (10), which could have confounded the results. Future studies should control for hand movements in order to reaffirm the precise contribution of BA44 in MR. Secondly, due to the use of minimal number of channels, our investigation focused primarily on the right frontal and prefrontal areas, while other brain areas, in particular the left frontal regions, might also be implicated in MR (20). So, future studies should employ a larger number of channels in order to allow a more extensive coverage of cortical regions. Thirdly, children of different age groups could be included in a crosssectional study to establish the age at which MR performance becomes mature and adultlike at both behavioural and neural levels. Fourthly, longitudinal studies could also be employed in the future to track any changes in the development of MR performance.

\section{MATERIALS AND METHODS}

\section{Participants}

Altogether 56 right-handed preschoolers participated in this study. Parents of these children provided written informed consent and were informed verbally of the purpose of the study and the safety of the fNIRS experiments. The University Ethics Committee approved the experiment. Eight participating children failed to complete the experiment and were thus excluded from this study. Among the 48 children who completed the experiment (aged between 49 and 75 months, $\mathrm{M}=66.15$ months, $\mathrm{SD}=7.20$ months; 24 girls), 18 preschoolers passed 17 (out of 18) testing items and were included in the High Performance (HP) Group $(N 1=18$; Mean Age $=68.89$ months, $\mathrm{SD}=5.69$ months; 13 girls). Another 18 preschoolers who failed at least one trial from each of the three blocks, thus passing only 15 or fewer testing items, were included in the Low Performance (LP) Group (N2 = 18; Mean Age $=63.11$ months, SD $=7.34$ months; 6 girls). The remaining 12 preschoolers who passed exactly 16 (out of 18) testing items were classified into the marginal group and were excluded from data analysis. No significant age difference was found between the HP and LP groups.

\section{Materials}

The MR task in this study, modified from the version developed by Krüger et al. (8), contained 14 original pictures and four extra pictures. As shown in Fig. 1, the target and test stimuli were picture cards attached onto a test book, presented to the participant on a table. The test stimulus (positioned on the right hand side) was loosely attached to the test book, in such a way that the participant could manipulate by rotating it. Unlike Krüger et al.'s study (8), computer tasks were not employed in this study, as most of the participants had no experience in using a touchscreen monitor.

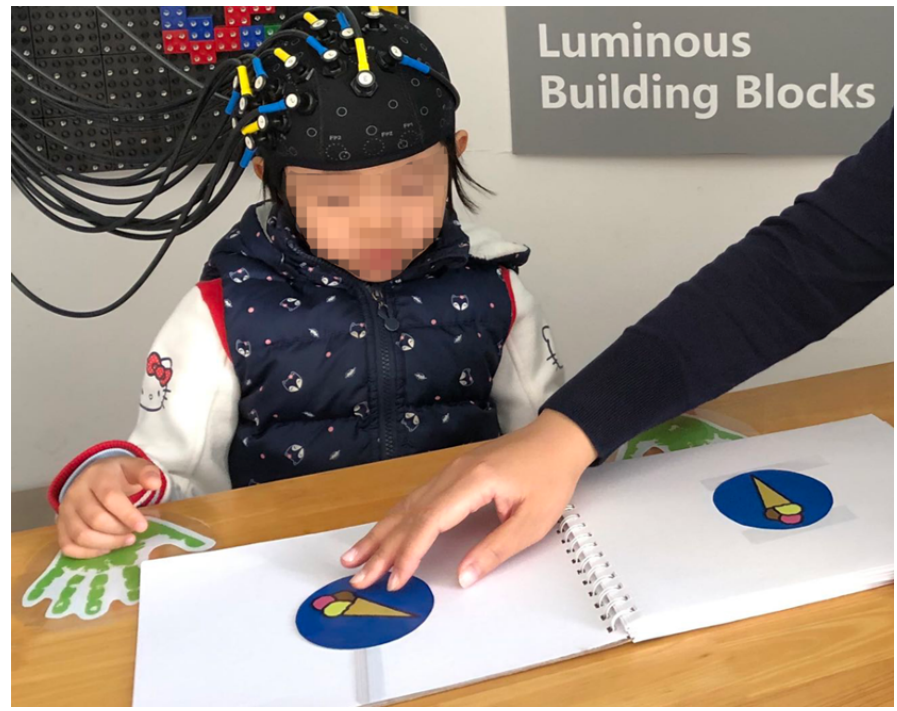

Fig. 1. Stimuli used in the mental rotation (MR) task. The participant was instructed to rotate the test stimulus to match the unrotated target stimulus.

\section{Procedure}

Rapport-building. The participants were informed about the fNIRS experiment in terms of an invitation to play games. Once the children gave their consent to participate, the experimenter read a picture book with the children while an experienced technician assisted the children put on the fNIRS equipment (see Fig. 1). The children were encouraged to report any uncomfortable feelings, so that the technician could adjust the equipment for them. The children were allowed to withdraw from the experiment anytime without negative consequences.

Cap placement. Child caps accompanied by the NIRS instrument (Oxymon Mk III, Artinis, The Netherlands) were used. The cap is a highly stretchable soft headwear that covers the entire head, with prefixed locations for optodes, much like an EEG cap. The cap has digitised optode positions to illustrate the parts of brain being recorded from.

The cap placement procedure involved making general head measurements to decide the size of NIRS cap to be used for each 
participant. Both small (S) and extra-small (XS) NIRS caps were used for the Chinese preschoolers in this study. The technician performed the cap placement, hair manipulation and tossing, as well as the installation of optodes (based on the 10/20 system). Additional colourful hairbands were used to keep the cap in place and to prevent slipping. As the cap placement procedure took approximately half an hour, children were engaged in storybook reading with an experienced preschool teacher during this period.

Task-setting. The stimuli followed the setting described in the experiment by Krüger et al. (8): One stimulus was not rotated (target stimulus, presented on the left side of the test book) while the other one was rotated clockwise to one of the following angles: $45^{\circ}, 90^{\circ}$, $135^{\circ}, 225^{\circ}, 270^{\circ}$ or $315^{\circ}$ (test stimulus; presented on the right side). The target and test stimuli were identical except for orientation. The participants were tested one by one, in the presence of the experimenter, one technician and a recorder. The participants were seated facing the table and were asked to make the test stimulus match the target stimulus by rotating the former along the shortest path. For example, if the test stimulus was at $90^{\circ}$ to the target stimulus, it would be considered as a correct solution to rotate the test stimulus anticlockwise by $90^{\circ}$ but an incorrect solution to rotate it $270^{\circ}$ clockwise. Number of correct trials and fNIRS data were recorded for analysis. The experiment was divided into training and test sessions.

Training session. The training session consisted of four trials. The experimenter explained to children how the first trial should be performed with the following instructions: "Here is an upright duck [experimenter pointing the target stimulus on the left] and here is a duck fallen on its side [pointing the test stimulus on the right]. Now let us help this duck get back on its feet as soon as possible. We can help him get up this way [rotating the test stimulus via the shortest route]. However, if you do it like this [rotating the test stimulus via a more distant route], the duck will be unhappy. So, please do not do it this way." The children were then asked to perform the remaining three training trials, during which the experimenter corrected them upon any mistakes. When a child made a mistake, i.e. chose the more distant route, the experimenter would repeat the original instructions and ask the child to repeat the corresponding trial. If the child made the same mistake again, he/she would be asked to perform all training trials again.

Test session. The test session consisted of 18 trials (18 different stimulus pairs) divided into three task blocks, each of which preceded a rest block (see Fig. 2). In each trial, a target (unrotated) stimulus was presented on the left side of the table while a test stimulus, rotated to one of the six aforementioned angles, was presented on the right side of the table. The trials were randomised in each block. No trials were repeated.

As in the training session, the children were instructed to rotate the test stimulus to match the target stimulus. No help or further instructions were given.

\section{Data acquisition, processing and analysis}

In this study, a multiple-channel fNIRS system (OxyMon Mk III, Artinis, The Netherlands) was used to simultaneously measure the concentration changes of oxygenated haemoglobin ( $\mathrm{HbO})$, deoxygenated haemoglobin $(\mathrm{HbR})$ and total haemoglobin $(\mathrm{HbT})$ in the participants. Two wavelengths in the near-infrared range, namely $760 \mathrm{~nm}$ and $850 \mathrm{~nm}$, were used to measure the changes in optical density which were then converted into changes in the concentration of $\mathrm{HbO}$ and $\mathrm{HbR}$ using the modified Beer-Lambert law.

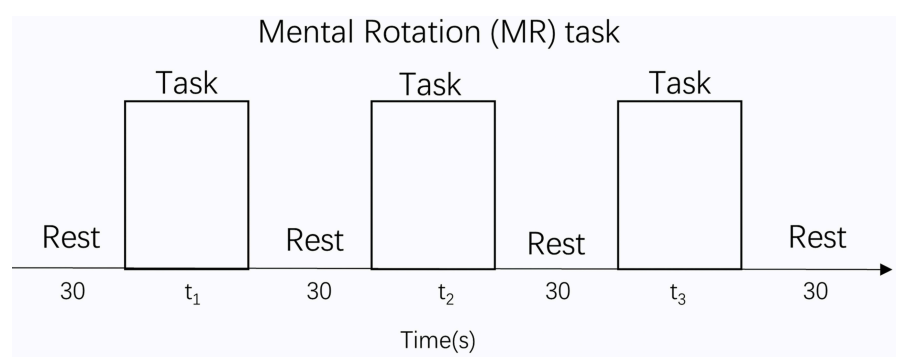

Fig. 2. The experimental paradigm consisted of a periodic block design composed of three mental rotation task blocks alternated with four 30 -second rest blocks. Experiment time $=\mathrm{t}_{1}+\mathrm{t}_{2}+\mathrm{t}_{3}$.

Seventeen fNIRS channels were used and located following the international 10/20 system for EEG, with a $2.5 \mathrm{~cm}$ distance between adjacent emitter-detector pairs. The regions of interest (ROIs) were located at Brodmann Areas (BAs) 6, 8, 9, 10, 40 and 44 (see Fig. 3). Previous studies have shown that these areas might be activated during cognitive shifting and other cognitive activities in preschoolers (11). For all participants, ten channels were located in the right frontal cortex and seven channels were located in the prefrontal cortex (Fig. 3). In particular, channels 1 and 9 were located at BA 6, channel 10 at BA 8, channels $11,12,14,16$ at BA 9, and channels $13,15,17$ at BA 10 , channel 4 at BA 40 and channels $2,3,5,6,7,8$ were located at BA 44 in the right inferior frontal cortex.
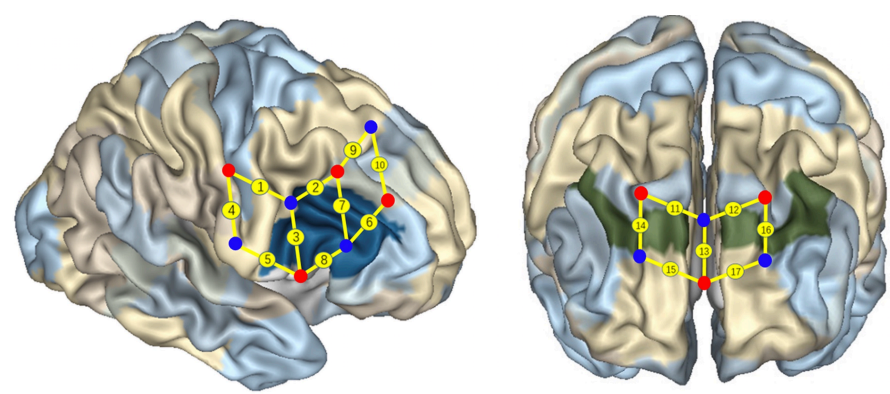

Fig. 3. Localisation of regions of interest. The numbers on small spheres on the brain map indicate the 17 channels. Channel localisation was based on the upper central probe, which was anchored at $\mathrm{Fz}$ according to the international 10/20 system and was located at the midpoint between channels numbers 11 and 12 . Channels 1 and 9 were located in BA 6, channel 10 was located in BA 8, channels 11, 12, 14 and 16 were located in BA 9, channels 13, 15, 17 were located in BA 10, channel 4 was located in BA 40, and channels 2, 3, 5, 6, 7 and 8 were located in the right inferior frontal cortex (IFC) (BA 44)

A subject-specific differential path-length factor (DPF) constant was calculated based on the age of each participant (23). The sampling rate was set at $50 \mathrm{~Hz}$ for data acquisition. Some of Homer2 NIRS processing package functions were applied to perform the data analysis using MATLAB (Mathworks, MA USA) (24). All incorrect trials were discarded from the analysis. The raw optical intensity data series were converted into changes in optical density (OD). The discrete wavelet transform was applied to every channel data series to remove motion artefacts, with the tuning parameter $(\alpha)$ of wavelet filtering set at 0.1 . To reduce slow drifts and highfrequency noise, a bandpass filter (third-order Butterworth filter) with cut-off frequencies of $0.01-0.3 \mathrm{~Hz}(25)$ was then applied to the data. The OD data were then converted into concentration changes of $\mathrm{HbO}$ and $\mathrm{HbR}$. Based on previous research (11), these values were then converted into z-scores.

Individual data were processed using MATLAB 2013b. The mean of $\mathrm{HbO}$ and $\mathrm{HbR}$ were calculated for each rest block and each 

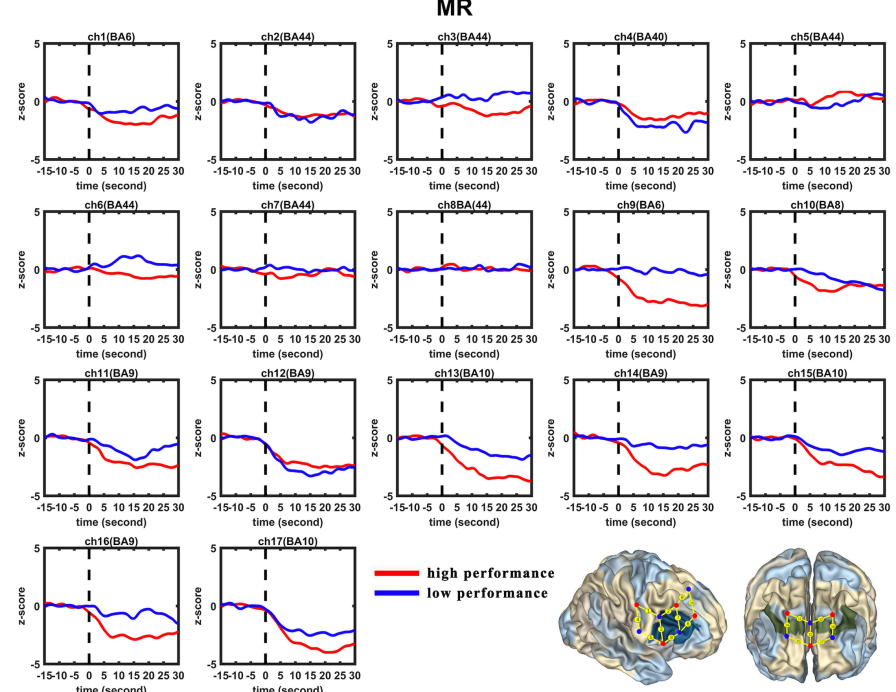

Fig. 4. Temporal changes in $\mathrm{HbO}$ concentration in the 17 channels during the mental rotation task. From left to right are channels 1 to 17 . The $\mathrm{HbO}$ data for the High and Low Performance groups are shown in red and blue lines respectively.
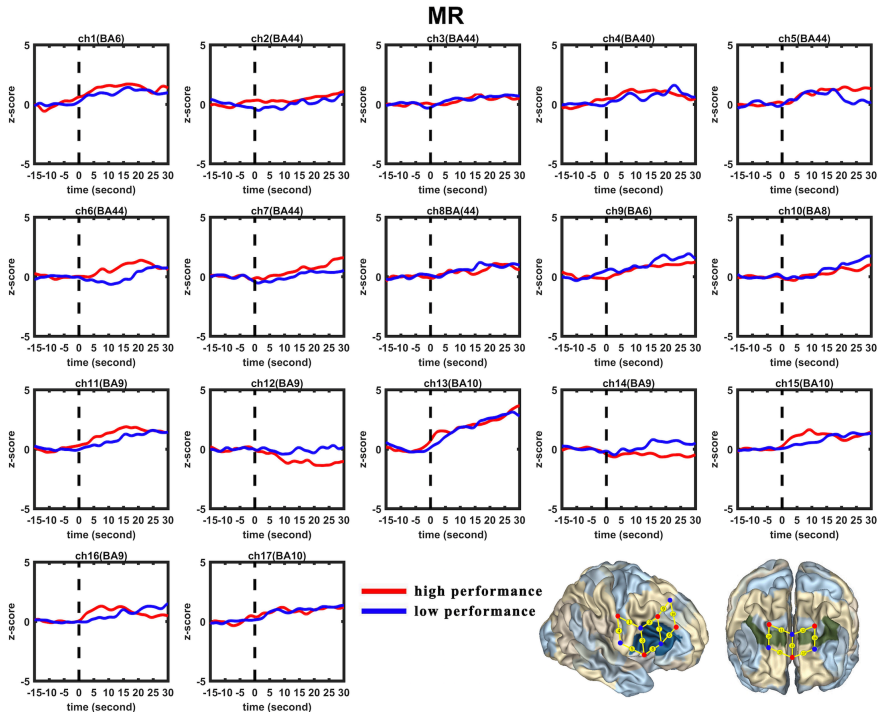

Fig. 5. Temporal changes in HbR concentration in the 17 channels during the mental rotation task. From left to right are channels 1 to 17 . The HbR data for the High and Low Performance groups are shown in red and blue lines respectively.

task block separately for each participant. By subtracting the mean ( $\mathrm{HbO}$ or $\mathrm{HbR}$ ) of the rest block from the corresponding value of succeeding task block, $\Delta \mathrm{HbO}$ and $\Delta \mathrm{HbR}$ were obtained for each task block. Then, mean of mean $\Delta \mathrm{HbO}$ and mean of mean $\Delta \mathrm{HbR}$ values were calculated by averaging across the three task blocks for each participant. Finally, the mean of mean $\Delta \mathrm{HbO}$ and $\Delta \mathrm{HbR}$ values across all channels were compared using $t$-tests between the HP and LP groups using SPSS. The General Linear Model (GLM) analysis used to predict $\Delta \mathrm{HbO}$ and $\Delta \mathrm{HbR}$ in each channel was conducted in $\mathrm{R}\left(Y_{\Delta H b O}=a X_{\text {time }}+b\right)$. The results are presented in Tables $\mathbf{1}$ to $\mathbf{4}$, Fig. 4 and Fig. 5.

\section{REFERENCES}

1. R. N. Shepard, J. Metzler, Mental rotation of three-dimensional objects. Science 171, 701-703 (1971)
2. C. Hoppe, K. Fliessbach, S. Stausberg, J. Stojanovic, P. Trautner, C. E. Elger, B. Weber, A key role for experimental task performance: Effects of math talent, gender and performance on the neural correlates of mental rotation. Brain Cogn. 78, 14-27 (2012).

3. J. M. Zacks, Neuroimaging studies of mental rotation: A meta-analysis and review. J. Cogn. Neurosci. 20, 1-19 (2008).

4. K. Jordan, H. J. Heinze, K. Lutz, M. Kanowski, L. Jäncke, Cortical activations during the mental rotation of different visual objects. Neurolmage 13, 143-152 (2001).

5. M. S. Cohen, S. M. Kosslyn, H. C. Breiter, G. J. DiGirolamo, W. L. Thompson, A. K. Anderson, S. Y. Bookheimer, B. R. Rosen, J. W. Belliveau, Changes in cortical activity during mental rotation. A mapping study using functional MRI. Brain 119, 89-100 (1996).

6. S. Schöning, A. Engelien, H. Kugel, S. Schäfer, H. Schiffbauer, P. Zwitserlood, E. Pletziger, P. Beizai, A. Kersting, P. Ohrmann, R. R. Greb, W. Lehmann, W. Heindel, V. Arolt, C. Konrad, Functional anatomy of visuo-spatial working memory during mental rotation is influenced by sex, menstrual cycle, and sex steroid hormones. Neuropsychologia 45, 3203-3214 (2007).

7. A. Frick, K. Ferrara, N. S. Newcombe, Using a touch screen paradigm to assess the development of mental rotation between $3 \frac{1}{2}$ and $5 \frac{1}{2}$ years of age. Cogn. Process. 14, 117127 (2013).

8. M. Krüger, M. Kaiser, K. Mahler, W. Bartels, H. Krist, Analogue mental transformations in 3year-olds: Introducing a new mental rotation paradigm suitable for young children. Infant Child Dev. 23, 123-138 (2014).

9. A. R. Aron, S. Monsell, B. J. Sahakian, T. W. Robbins, A componential analysis of task-switching deficits associated with lesions of left and right frontal cortex. Brain 127, 1561-1573 (2004).

10. G. Rizzolatti, L. Fogassi, V. Gallese, Motor and cognitive functions of the ventral premotor cortex. Curr. Opin. Neurobiol. 12, 149-154 (2002).

11. Y. Moriguchi, K. Hiraki, Neural origin of cognitive shifting in young children. Proc. Natl. Acad. Sci. U.S.A. 106, 6017-6021 (2009).

12. S. Geyer, T. Schormann, H. Mohlberg, K. Zilles, Areas 3a, 3b, and 1 of human primary somatosensory cortex. Part 2 . Spatial normalization to standard anatomical space. Neurolmage 11, 684-696 (2000).

13. T. Hanakawa, M. Honda, N. Sawamoto, T. Okada, Y. Yonekura, H. Fukuyama, H. Shibasaki, The role of rostral brodmann area 6 in mental-operation tasks: An integrative neuroimaging approach. Cereb. Cortex 12, 1157-1170 (2002).

14. C. L. Raye, M. K. Johnson, K. J. Mitchell, J. A. Reeder, E. J. Greene, Neuroimaging a single thought: Dorsolateral PFC activity associated with refreshing just-activated information. Neurolmage 15, 447-453 (2002).

15. E. Brunet, Y. Sarfati, M.-C. Hardy-Baylé, J. Decety, A PET investigation of the attribution of intentions with a nonverbal task. Neurolmage 11, 157-166 (2000).

16. H. C. Leung, J. C. Gore, P. S. Goldman-Rakic, Sustained mnemonic response in the human middle frontal gyrus during on-line storage of spatial memoranda. J. Cogn. Neurosci. 14, 659671 (2002).

17. H. L. Gallagher, A. I. Jack, A. Roepstorff, C. D. Frith, Imaging the intentional stance in a competitive game. Neurolmage 16, 814-821 (2002).

18. J. B. Pochon, R. Levy, P. Fossati, S. Lehericy, J. B. Poline, B. Pillon, D. L. Bihan, B. Dubois, The neural system that bridges reward and cognition in humans: An fMRI study. Proc. Natl. Acad. Sci. U.S.A. 99, 5669-5674 (2002).

19. J. X. Zhang, H.-C. Leung, M. K. Johnson, Frontal activations associated with accessing and evaluating information in working memory: An fMRI study. Neurolmage 20, 1531-1539 (2003).

20. S. D. Slotnick, L. R. Moo, Prefrontal cortex hemispheric specialization for categorical and coordinate visual spatial memory. Neuropsychologia 44, 1560-1568 (2006).

21. J. A. Yoon, I. J. Kong, J. Choi, J. Y. Baek, E. J. Kim, Y. I. Shin, M. H. Ko, Y. B. Shin, M. J. Shin, Neural compensatory response during complex cognitive function tasks in mild cognitive impairment: A near-infrared spectroscopy study. Neural Plast. 2019, 7845104 (2019).

22. P. Pinti, I. Tachtsidis, A. Hamilton, J. Hirsch, C. Aichelburg, S. Gibert, P. W. Burgess, The present and future use of functional near-infrared spectroscopy (fNIRS) for cognitive neuroscience. Ann. N. Y. Acad. Sci. 1464, 5-29 (2018).

23. A. Duncan, J. H. Meek, M. Clemence, C. E. Elwell, P. Fallon, L. Tyszczuk, M. Cope, D. T. Delpy, Measurement of cranial optical path length as a function of age using phase resolved near infrared spectroscopy. Pediatr. Res. 39, 889-894 (1996).

24. T. J. Huppert, S. G. Diamond, M. A. Franceschini, D. A. Boas, HomER: A review of time-series analysis methods for near-infrared spectroscopy of the brain. Appl. Opt. 48, D280-D298 (2009)

25. D. T. Delpy, M. Cope, P. van der Zee, S. Arridge, S. Wray, J. Wyatt, Estimation of optical pathlength through tissue from direct time of flight measurement. Phys. Med. Biol. 33, 14331442 (1988).

Acknowledgements: Funding: This work was supported by the Shenzhen Fundamental Research Project (JCYJ20170412111316339) and the Shenzhen Talent Peacock Team Plan (827-000083). Author contributions: D.D. Wu, J.F. Yang, S. Xie, and J.T. Luo collected the data. D.D. Wu and H. Li designed the experiment. J.F. Yang and C.Q. Chang analysed the data. D.D. Wu, J.F. Yang, C.Q. Chang and $\mathrm{H}$. Li drafted the manuscript. Competing interests: The authors declare that they have no competing interests. Data and materials availability: The data and materials of this experiment could be made available upon request to the corresponding author.

The authors are very grateful to Madam WANG Weili, the Principal of Shenzhen Lotus No. 2 Village Kindergarten, for her excellent help in polishing the experimental procedures and in recruiting the participants. Thanks also go to Dr. Frank Zhu for his kind assistance in developing the research idea. 